\title{
O Look nos filmes Direito de Amar, Azul É A Cor Mais Quente \\ e \\ Moonlight: sob a luz do luar ${ }^{1}$
}

The Look in the movies A single man, Blue is the Warmest Color and Moonlight

Pedro Felipe Pinho Souza

Doutorando em Artes Visuais - Instituto de Artes, Unicamp pedropinho88@gmail.com ORCID: https://orcid.org/0000-0003-4318-1510

\section{RESUMO:}

Este artigo analisará a utilização da cor na produção e pós-produção cinematográfica. Primeiro, é importante investigar a nomeação e classificação dos termos utilizados na área para os processos de manipulação da cor na imagem. Correção de cor, color grading, colorização digital, look, correções primárias, correções secundárias são termos que serão conceituados e analisados. Posteriormente, o artigo irá focar exclusivamente no look. Através de um apanhado histórico, o artigo busca mostrar o desenvolvimento dos significados na cor na imagem. Três filmes serão analisados para demonstrar a importância da utilização criativa da cor na construção narrativa da obra cinematográfica.

Palavras-chave: Look. Correção de cor. Colorização digital.

\section{ABSTRACT:}

This article analyzes the use of color in film production and postproduction. Three films will be used as examples to demonstrate the importance of creative color use in the narrative construction of film. First, it is important to investigate the naming and classification of terms used for color manipulation processes in the image. Color correction, color 
grading, digital colorization, look, primary corrections, secondary corrections are terms that will be analyzed and pointed. Subsequently, the article focus exclusively on the look. Through a historical account of the modification of the cinematographic image, the article aims at showing the development of the meanings that color in the image has borne throughout the history of the seventh art.

Keywords: Look. Color correction. Digital colorization.

Artigo recebido em 10/01/2019 Artigo aprovado em 01/03/2019

\section{Colorização digital, correção de cor}

Presente nas mais diversas áreas, estudar a cor é um desafio para qualquer ser humano, pois está em todos os lugares e pode ser observada sob diferentes aspectos e áreas do conhecimento. Luciano Guimarães é categórico ao afirmar que o estudo da cor transita da "filosofia à psicologia da percepção, passando pela fisiologia, física, estética etc." (GUIMARÃES, 2001, p. 3), e, por esse caráter interdisciplinar, o fenômeno cromático requer um estudo que leve em conta essa característica.

Espectro visível, luz, radiação, onda, as definições são amplas e abrangem diversas áreas do conhecimento. A cor é uma sensação causada pela radiação eletromagnética. Essa radiação tem o comprimento de onda presente no espectro visível, que denominamos luz. O debate e os termos utilizados, misturando física, biologia, psicologia entre outras áreas, podem parecer complexos, ainda mais se a busca é por compreender a cor inserida no cinema, uma arte que pressupõe investigações simbólicas e filosóficas, e não exatas sobre a cor.

SOUZA,Pedro Felipe Pinho. 0 Look nos filmes Direito de Amar, Azul É A Cor Mais Quente e Moonlight: sob a luz do luar.

PóS:Revista do Programa de Pós-graduação em Artes da EBA/UFMG. v.9, n.17: mai. 2019. Disponivel em <https://eba.ufmg.br/revistapos $>$

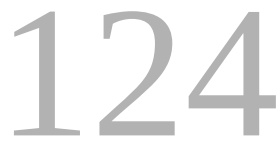


Sentimos cor e a sentimos primeiramente pelo órgão da visão, o olho. Cada sensação gerada produz expectativas, desejos, vontades, associações, medos e alegrias diferentes em cada indivíduo e, consequentemente, será interpretada de modo diferente por cada cultura e sociedade. A partir disso, um leque de possibilidades se abre para a utilização da cor. Além de suas capacidades físicas e da nossa decodificação pela visão, a cor existe no mundo, e a interação humana com os diversos elementos, das mais variadas cores, está inserida em cada cultura. Ao associar determinada sensação a uma cor, cada sociedade construiu e desconstruiu suas vivências e realidades.

No universo cinematográfico, alguns profissionais são responsáveis por pensar e inserir elementos em cena, e sua preocupação com as cores dos elementos e as suas possibilidades suscitam questões sobre como conduzir uma narrativa por meio das cores no filme. O visual da imagem cinematográfica decorrente de escolhas simbólicas feitas pelos profissionais envolvidos no desenvolvimento da imagem é chamado de look. O look é, pois, o objeto principal de investigação deste trabalho.

O processo de colorização digital utilizado em produções televisivas e cinematográficas é relativamente novo, surge depois dos avanços da informática e popularização do computador, por volta do final da década de 1990 e início dos anos 2000. Para Prince (2004), dois filmes marcam o início desse processo: Pleaseantville: a vida em preto e branco, de Gary Ross (1998) e E aí meu irmão, cadê você?, dos irmãos Ethan e Joel Cohen (2000). O primeiro tem sua importância por ser um filme gravado em cores e descolorido digitalmente para tornar-se preto e branco; já o segundo, modifica as cores das paisagens e locações para, assim, homogeneizar os planos sob uma mesma identidade visual e conceitual, o chamado look pelos profissionais da área: “[...] looks são estilizações visíveis de uma imagem com a intenção de criar um estado de espírito claro ou referência". (HURKMAN,

SOUZA,Pedro Felipe Pinho. o Look nos filmes Direito de Amar, Azul É A Cor Mais Quente e Moonlight: sob a luz do luar.

PóS:Revista do Programa de Pós-graduação em Artes da EBA/UFMG. v.9, n.17: mai. 2019. Disponivel em <https://eba.ufmg.br/revistapos $>$

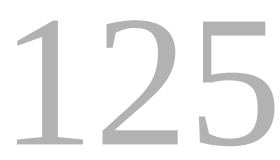


2014, p. 14). O look de um filme é, portanto, um visual proposto pelos profissionais, relacionado à cor em um filme. Entre esses profissionais, há o colorista ${ }^{2}$ durante o processo de colorização digital.

O termo colorização digital é utilizado essencialmente para se referir à técnica de "pintura", realizada em imagens digitais. Sua maior utilização se dá em fotografias em preto e branco, que são coloridas com a utilização de software, como o Adobe Photoshop. ${ }^{3}$ No cinema, a colorização digital é o termo comumente utilizado para definir a técnica de matização de filmes em preto e branco.

Contudo, a colorização digital cinematográfica nem sempre será utilizada para matizar imagens em preto e branco. Se o processo permite manipular e controlar os pixels de uma imagem, modificando-os sem restrições; diversas utilizações artísticas podem surgir desse processo no cinema. O controle de todos os pixels da imagem cinematográfica apresenta-se ao utilizador desse processo.

O processo e o surgimento das técnicas utilizadas pelos aparatos digitais para coloração da imagem não se distanciam, quanto às suas utilizações estética e simbólica, daquelas apresentadas nos moldes analógicos ao longo da história do cinema. Entretanto possibilitam mais velocidade na realização e mais controle sobre a imagem cinematográfica. Esse controle, consequentemente, trouxe algumas novas possibilidades criativas, por exemplo, a criação de diferentes looks para os filmes.

Atualmente, como relatado por Edgar Moura (2016), muitos acreditam que o trabalho do colorista se limite a balancear e equalizar os planos, otimizar as imagens de modo a não deixar erros ou exageros cometidos durante a gravação serem percebidos, algo como "consertar a imagem", uma função de "controle de qualidade". Essa é, realmente, uma de suas funções, porém, não a principal. O principal trabalho do colorista é propor o look, isto é, uma identidade visual para a obra.

SOUZA,Pedro Felipe Pinho. 0 Look nos filmes Direito de Amar, Azul É A Cor Mais Quente e Moonlight: sob a luz do luar.

PóS:Revista do Programa de Pós-graduação em Artes da EBA/UFMG. v.9, n.17: mai. 2019. Disponivel em <https://eba.ufmg.br/revistapos $>$

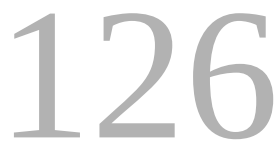


Os teóricos e mesmo os profissionais da área divergem quanto a como nomear e dividir as diversas etapas do processo de colorização digital, mesmo nos termos em inglês. A correlação para com a língua portuguesa ainda é imprecisa, o que dificulta as pesquisas na área. A fase da pós-produção cinematográfica que intervém e modifica a imagem filmada por meio da manipulação dos pixels é chamada, no inglês, de color correction ou de color grading. Alexis Van Hurkman, colorista norte-americano, faz uma diferenciação entre esses dois termos:

Eu diria que color correction se refere a um processo que é mais técnico em sua natureza, de fazer ajustes para corrigir problemas qualitativos claros na imagem, levando-a a um estado bastante neutro, enquanto grading refere-se a um processo mais intensivo de desenvolvimento de um estilo apropriado geral para a imagem, em relação às necessidades narrativas e artísticas pretendida (HURKMAN, 2011, p. ix, tradução nossa). ${ }^{4}$

Hurkman já dá sinais, portanto, da importância que o colorista tem no processo de construção da imagem cinematográfica. Os termos, porém, ainda precisam de atenção, pois podem gerar confusão. Ao separar os dois termos em dois conceitos diferentes, o autor também estabelece diferentes etapas para o processo. Uma primeira, com um caráter técnico, e, uma segunda, com um viés artístico. Todavia o trabalho como um todo, que englobaria essas duas fases, ainda não possui uma nomenclatura precisa, ora sendo chamado de color correction, ora grading. Neste artigo, o termo utilizado para se referir ao trabalho como um todo será colorização digital da obra cinematográfica. O Esquema 1 mostra o encadeamento dos termos e como eles são referenciados.

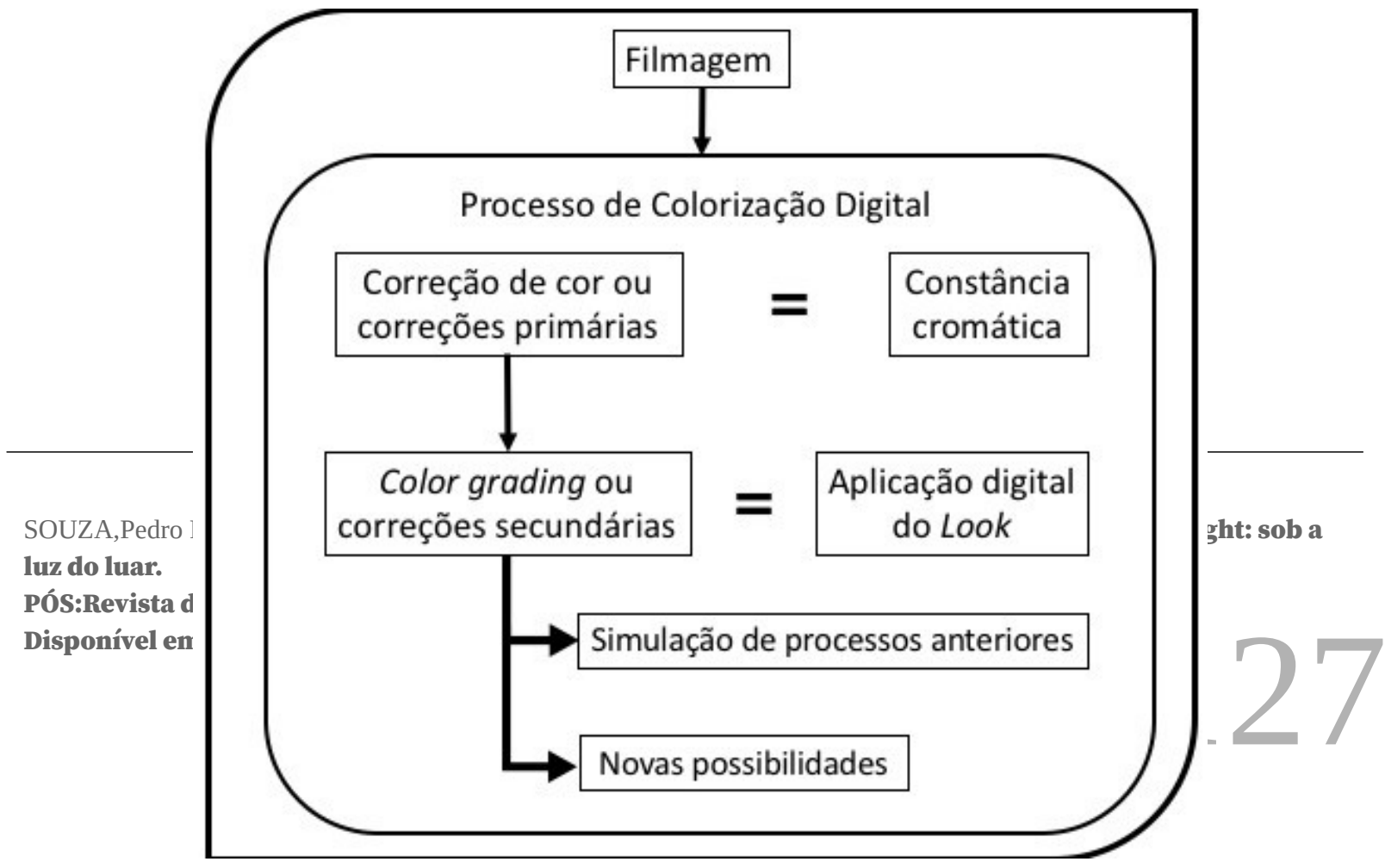


Esquema 1 - Encadeamento dos termos e expressões - 2019

Fonte: Imagem produzida pelo autor

Tem-se, portanto, o processo de colorização digital, que envolve duas fases distintas: correção de cor ou correções primárias, que tem como objetivo garantir uma constância cromática para a obra; e color grading ou correções secundárias, cujo objetivo é aplicar digitalmente o look proposto. Esse segundo processo possui duas características distintas, a simulação dos processos de colorização anteriores, realizados ao longo da história do cinema e novas possibilidades que surgem com a ferramenta digital.

Pensar o look de um filme, portanto, é pensar o segundo processo, chamado de color grading por Hurkman. O visual que atende às necessidades narrativas e artísticas é o look. As possibilidades de manipulação da cor depois do surgimento e controle do pixel trouxeram aos diretores uma nova via criativa. Os diferentes looks podem estar associados às narrativas, aos personagens, seus humores, aos ambientes da obra, etc.

O sentido da cor forma-se em decorrência das relações estabelecidas no próprio discurso, através das suas conexões com as formas, atmosferas, estado de alma, disposições tímicas (euforia, aforia, disforia), distribuições espaciais (topologia), e ao próprio encadeamento de acontecimentos que caracteriza a narrativa [...] (BARROS, 2012, p. 77).

SOUZA,Pedro Felipe Pinho. o Look nos filmes Direito de Amar, Azul É A Cor Mais Quente e Moonlight: sob a luz do luar.

PóS:Revista do Programa de Pós-graduação em Artes da EBA/UFMG.v.9, n.17: mai. 2019. Disponivel em <https://eba.ufmg.br/revistapos $>$ 
Para criar esse visual, o colorista não trabalha sozinho, mas em conjunto com o fotógrafo, cenógrafo, figurinista e o diretor geral. O primeiro é o responsável por iluminar a cena, por colocar os focos de luz e enquadrar. O segundo é responsável pelos objetos da cena, pela cenografia, escolha das cores dos ambientes, disposição dos objetos. O terceiro (figurinista) é responsável pelo figurino das personagens, suas roupas e adereços. O cenógrafo e o figurinista estão sob a responsabilidade do diretor de arte, responsável geral por figurino, maquiagem, cenografia. Por último, o diretor geral, responsável pela ideia disparadora que irá unir os outros profissionais em torno de um mesmo tema. É o diretor que faz a conexão entre todos esses profissionais, o roteiro e outros elementos narrativos da obra; ele determina o caminho a ser seguido. Os outros profissionais e suas expertises podem auxiliar o diretor em suas escolhas, mas, no geral, a última palavra é dele.

Em uma arte que envolve diferentes profissionais de diversas áreas, a responsabilidade do colorista tem importância, em função de não haver como modificar a imagem cinematográfica após o fim de seu trabalho, diferentemente dos outros profissionais do processo de produção. Sua função, portanto, é assegurar a qualidade cromática final da obra.

A autenticidade da obra e os profissionais envolvidos no cinema podem suscitar debates sobre a importância de cada função no desenvolvimento da obra. Mais do que buscar uma ou outra função primordial, o cinema é uma obra coletiva e o reconhecimento das diferentes expertises é fundamental para essa arte. Há diversos profissionais na indústria cinematográfica que ainda buscam reconhecimento pelo viés artístico de seus trabalhos. O embate entre o caráter técnico e o artístico prejudica, por exemplo, profissionais responsáveis pelos efeitos digitais e os coloristas. ${ }^{5}$ O colorista não cria efeitos por uma tela verde como os responsáveis pela computação gráfica da obra. Todavia, mesmo elementos totalmente digitais, quando inseridos na imagem, precisam passar pelo processo de colorização digital, mais precisamente pela correção de cor. A colorização digital irá 
unir todos os elementos da imagem sob uma mesma identidade visual, e isso inclui os elementos totalmente digitais. Quando há atores interagindo com esses elementos, a verossimilhança só será alcançada se houver uma constância cromática entre universo real e universo digital. Nesse sentido, o colorista tem uma função técnica importante no desenvolvimento da obra de arte cinematográfica.

É nesses embates que a cor tem sua relevância. A cor aparece como componente intrínseco da realidade, do objeto, mas também é modelo numérico, passível de ser, portanto, digitalizada, transformada em simulacro. A técnica de aplicação de cores no ambiente do computador exige do colorista a subjetividade da escolha de cada cor para a imagem, não mais dentro do modelo numérico, mas como sensação. A cor inscrita nessa subjetividade é que alimenta a arte do colorista. Assim, a cor, real ou digital, funcionando como sensação na obra, traz uma subjetividade que é proporcionada pela técnica. A cor, em suma, aparece como elemento fundamental da imagem, elemento mínimo no pixel, modelo numérico e maquinário e como elemento máximo na imagem como pura sensação.

Não é de se estranhar, portanto, que, para chegar a esse "realismo", o cinema precise da cor, precise ser colorido. A cor é, nesse caso, ferramenta fundamental da mímese, parte integrante do objeto retratado que deve ser reproduzida, com fidelidade para que o objetivo do realismo seja atingido. “Logo, a cor pode ser considerada como simplesmente outro elemento que aproxima o cinema da realidade" (COSTA, 2011, p. 31).

A utilização da cor como elemento de verossimilhança e a técnica de correção de cor, têm, portanto, similaridades. Assim como a técnica de color grading, também traz a possibilidade de proporcionar prazer visual pela obra. Há, então, duas vertentes que se unem no processo de colorização digital: uma técnica, outra 
artística. Edmond Couchot (2003) entende que são as técnicas que dão acesso à arte, ou seja, o controle de determinada técnica irá desenvolver, ou mesmo produzir, novas formas de arte.

A imagem é uma atividade que coloca em jogo técnicas e um sujeito (operador, artesão ou artista, segundo cada cultura) operando com estas técnicas, mas possuidor de um saber-fazer que leva sempre o traço voluntário, ou não, de uma certa singularidade. Como operador, este sujeito controla e manipula técnicas através das quais vive uma experiência íntima que transforma a percepção que tem do mundo: a experiência tecnestésica (COUCHOT, 2003, p. 15, tradução nossa).

Além de artista, operador e artesão, uma outra definição aparece ao tratar do sujeito que opera com determinadas técnicas: o técnico. O colorista será encarado como o técnico responsável por operar um software que manipula os pixels da imagem cinematográfica. O software é a ferramenta do colorista. A função desse técnico não é encarada como artística por muitos, e o reconhecimento, como visto, acaba não vindo por parte de outros profissionais, que já têm a via artística de suas profissões bem delimitada. Philippe Dubois (2004, p. 57) também teoriza a respeito disso e declara: “[...] a invenção essencial é sempre estética, nunca técnica". Essa técnica, portanto, não está separada da "experiência íntima" que o colorista tem com a ferramenta, e, ao manipular e compreender a fundo, ela desenvolverá novas e diferentes possibilidades para sua utilização, distanciandose do caráter puramente técnico (se é que esse existe) e se aproximando de um viés artístico da utilização da ferramenta.

Assim, quanto mais capaz for um sistema para imitar fielmente o real em sua aparência, mais ele suscitará a proliferação de pequenas formas que minam tal potência de mimetismo, visando desconstruílo. Curiosa revanche da imagem sobre o instrumentalismo da máquina, como se estivéssemos diante de uma pulsão de subversão da figura proporcional à força de dominação do sistema (DUBOIS, 2004, p. 55).

SOUZA,Pedro Felipe Pinho. 0 Look nos filmes Direito de Amar, Azul É A Cor Mais Quente e Moonlight: sob a luz do luar.

PóS:Revista do Programa de Pós-graduação em Artes da EBA/UFMG.v.9, n.17: mai. 2019. Disponivel em < $\underline{\text { https://eba.ufmg.br/revistapos }>}$ 


\section{O look}

O desenvolvimento do look da obra, como dito, envolve diversos profissionais, porém, o termo look só é utilizado no momento de finalização, ou seja, somente quando o colorista entra em ação. O desenvolvimento do look envolve o aparecimento de uma segunda característica bastante peculiar do cinema digital. Ao buscar manter a verossimilhança por meio da mímese dos processos reais, em alguns casos, as técnicas digitais simulam características do próprio cinema e de seu desenvolvimento. A imagem cinematográfica possui características únicas que a diferencia de outras imagens, muito disso era em função dos diferentes negativos e revelações que foram sendo introduzidos ao longo de sua história, criando um leque de imagens características dessa arte. Essas imagens também podem ser simuladas pelas técnicas digitais. E a colorização digital, como tal, se responsabiliza por realizar esses simulacros, ou seja, produzir imagens como se tivessem sido filmadas com determinado tipo de negativo ou determinado tipo de revelação da película. Essa simulação da imagem analógica (no caso, uma emulação, um simulacro do processo de simulação do real) se tornou uma das primeiras funções do processo de colorização digital, reduzindo custos e acelerando os processos em comparação aos analógicos / fotoquímicos. O filme Moonlight: sob a luz do luar é um exemplo que será analisado ao final deste artigo.

Em seu livro Color Correction Look Book (2014), Hurkman demonstra como alcançar diversos looks, tendo como base imagens obtidas por meio de processos fotoquímicos. Um desses processos, bastante utilizado, chama-se bleach by-pass e consiste em reter a prata dos negativos durante a revelação para criar um efeito específico na imagem. Obviamente, não é possível reter a prata em processos digitais, portanto, simula-se digitalmente o visual da imagem fotoquímica. Como o resultado é satisfatório, pois compreende-se completamente o processo, diz-se emulação da película no digital. É o processo de colorização digital que gera esse efeito. E, por se tratar de um look, essa técnica é aplicada durante o color grading.

SOUZA,Pedro Felipe Pinho. 0 Look nos filmes Direito de Amar, Azul É A Cor Mais Quente e Moonlight: sob a luz do luar.

PóS:Revista do Programa de Pós-graduação em Artes da EBA/UFMG.v.9, n.17: mai. 2019. Disponivel em <https://eba.ufmg.br/revistapos $>$ 
A utilização do look para estabelecer o clima ou humor da obra está atrelada ao uso de determinadas cores e às referências simbólicas que elas podem adquirir. Essa utilização, no que concerne ao colorista e ao processo de colorização digital, diz respeito ao color grading. É a aplicação digital da proposta de look do filme. Determinadas cores em certos filmes amplificam e podem ser importantes na construção das narrativas, por exemplo, na utilização de tons de azuis, verdes e cinzas para o estilo de filmes de guerra, ou uma alta saturação e muitas cores para filmes infantis. Ao longo da história do cinema, pode-se observar a construção simbólica das cores atreladas aos estilos das narrativas contadas.

A cor, enquanto elemento a ser manipulado pelo colorista, pode assumir diversos valores simbólicos e conceder ao look a capacidade de modificar a percepção da obra. Os valores simbólicos podem ser os usuais e comumente estabelecidos, por exemplo, o vermelho atrelado ao amor ou o azul à frieza e depressão. No entanto, utilizações diferentes podem surgir, dependendo da criatividade dos responsáveis, não sendo, portanto, uma regra inquestionável a associação de determinado look a determinado discurso visual que se queira gerar.

Somente através da construção de uma história estética ampla do cinema - que leva em conta as analogias do passado e do presente podemos chegar a uma compreensão mais rica e crítica do que o cinema é, faz e pode fazer, particularmente agora que a imagem digital nos lembrou, mais uma vez, que a ontologia sensível do cinema é, e espero que continue a ser, uma questão aberta e premente $^{6}$ (YUMIBE, 2012, p. 152, tradução nossa).

O processo de colorização cinematográfica teve etapas analógicas durante muitas décadas. As filmagens em películas eram transferidas para o computador e, após os ajustes digitais, os filmes voltavam à película para distribuição e exibição. No entanto, era por esse processo que se tornou possível o acréscimo de efeitos especiais e um diálogo entre o computador e as imagens cinematográficas, porém, ainda refém da película e da exibição através de projetores analógicos.

SOUZA,Pedro Felipe Pinho. O Look nos filmes Direito de Amar, Azul É A Cor Mais Quente e Moonlight: sob a luz do luar.

PóS:Revista do Programa de Pós-graduação em Artes da EBA/UFMG.v.9, n.17: mai. 2019. Disponivel em < $\underline{\text { https://eba.ufmg.br/revistapos }>}$ 
O cinema também esteve, por muito tempo, dependente dos processos que ocorriam no set. O processo de filmagem era o cerne da arte cinematográfica; a imagem era criada e definida de acordo com as decisões e acordos tomados, ali, pelos participantes daquele processo. Depois da fase de produção, intervir no filme era difícil, visto que as possibilidades de manipulação eram pequenas.

Para baratear as outras fases (filmagem, distribuição, exibição, por exemplo), o cinema começa a tornar-se gradativamente totalmente digital. Em 2002, George Lucas filma Star Wars: Episódio II Ataque dos Clones, utilizando uma câmera digital (Sony's CineAlta HDW-F900), produzindo arquivos digitais e abandonando a película. As vantagens da imagem digital, segundo Prince (2011), recaem na habilidade de "ver" mais detalhes das sombras e de produzir imagens mais brilhantes, proporcionando cores mais saturadas e contrastadas na tela. Contudo, a imagem digital, em seu princípio, aparentava-se estranha aos olhos dos expectadores. 0 próprio Prince, em um artigo de 2004 (The Emergence of Filmic Artifacts: Cinema and Cinematography in Digital Era), conclui que "O visual ameno, granulado, levemente nebuloso da película parecerá tão estranho às próximas gerações de expectadores quanto o visual quente e forte do DV $^{7}$ parece-nos agora." (PRINCE, 2004, p. 33, tradução nossa).

Durante o processo de produção da obra, é preciso considerar os elementos e objetos presentes em cena na construção da imagem cinematográfica. Natalie Kalmus, principal nome da indústria da cor hollywoodiana no período do Technicolor, ${ }^{8}$ desenvolveu padrões e regras para a utilização de cor em filmes. Alguns desses padrões foram quebrados ou melhor desenvolvidos, mas uma ideia em especial chama a atenção, o desenvolvimento de uma paleta de cores que seria seguida pela obra. Desse modo, todos os profissionais envolvidos saberiam qual caminho seguir com relação a cor nas obras.

SOUZA,Pedro Felipe Pinho. O Look nos filmes Direito de Amar, Azul É A Cor Mais Quente e Moonlight: sob a luz do luar.

PóS:Revista do Programa de Pós-graduação em Artes da EBA/UFMG.v.9, n.17: mai. 2019. Disponivel em <https://eba.ufmg.br/revistapos $>$

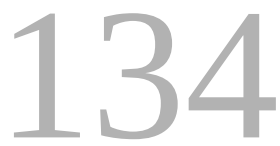


O artigo de Kalmus, Color Consciousness (1935), tornou-se o primeiro manual de utilização de cores em filmes, apesar do apelo aos usos convencionais da cor nas obras, Kalmus traz à tona a importância da narrativa da obra, e, para ela, a cor não poderia chamar mais atenção do que o enredo. O intuito maior e genuíno de Kalmus foi buscar construir para o cinema uma relação intrínseca entre as cores e a narrativa, fazendo o trabalho produzido pela Technicolor ganhar uma importância sem precedentes.

Para conseguir "domesticar" a utilização das cores em filmes, Kalmus, em seu artigo, elencou quatro regras a serem seguidas em produções coloridas. A primeira regra, e mais elucidativa, dizia que as paletas cromáticas dos filmes deveriam ser coordenadas com a ação dramática. A segunda limitava a utilização de cores muito claras e saturadas, em detrimento da utilização de cores mais "naturais". A terceira regra complementava a primeira, permitindo a utilização de certas cores somente em favor da narrativa; e a quarta e última, complementava a segunda ao propor que os elementos da mise-en-scène deveriam estar organizados e coordenados para não causar distrações, pois essas poderiam diminuir a compreensão da narrativa.

Assim, Kalmus desenvolveu algumas regras que são aplicadas até hoje em produções cinematográficas, em especial no desenvolvimento de paletas de cor atreladas à narrativa. No entanto, outras regras estão sendo quebradas e autores como Pedro Almodóvar utilizam cores saturadas em suas obras sem prejuízo à compreensão da narrativa.

As paletas de cores são utilizadas em filmes, atualmente, e são determinadas antes do início da produção da obra, servindo como guia para os responsáveis pelas cores dos filmes. É seguindo esse esquema que o colorista irá propor o look. Essa paleta pode vir de diferentes referências e ser constituinte da narrativa fílmica e modificar elementos perceptivos da imagem, como o contraste, saturação. Esquemas de cor foram organizados por diferentes guias e manuais e 
podem ser encontrados em diferentes sites na internet. ${ }^{9}$ Paletas monocromática, análoga e complementar são as que têm mais exemplos. Caso seja preciso romper com a harmonia dessas paletas na narrativa, uma cor diferente do padrão será introduzida.

Exemplificando, a paleta monocromática pode ser vista em determinadas cenas dos filmes Matrix (Lana e Lilly Wachowski, 1999), Traffic (Steven Soderbergh, 2001), e Só Deus perdoa (Nicolas Winding Refn, 2013), conforme a Figura 1. As atribuições de significado para as escolhas são difíceis de precisar, pois o processo criativo de cada obra é único, mas é possível fazer considerações com análises atentas a determinadas utilizações.

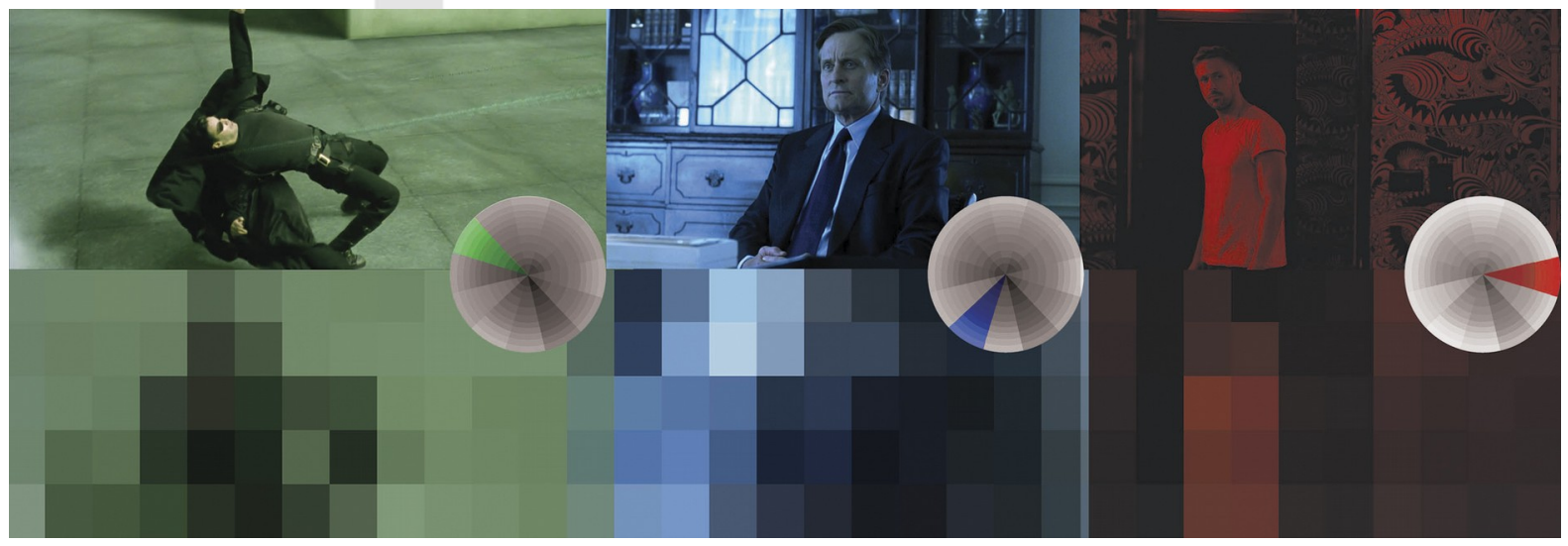

Figura 1 - Matrix (1999), Traffic (2001) e Só Deus perdoa (2013)

Legenda: (c) Frame do filme Matrix, Lana e Lilly Wachowski, 1999 (esquerda). | ( ) Frame do filme Traffic, Steven Soderbergh, 2001(centro) | @ Frame do filme Só Deus perdoa, Nicolas Winding Refn, 2013.

Fonte: Imagem produzida pelo autor Já paletas de cores análogas são uma especialidade do diretor Wes Anderson e podem ser vistas em Moonrise Kingdom (2012) e Grand Hotel Budapeste (2014), por exemplo. Cores análogas são cores próximas dentro do círculo cromático, como vermelhos, amarelos e laranjas ou azuis e verdes.

As paletas de cores complementares são das mais utilizadas e opõem duas cores do círculo cromático. Um exemplo clássico nesses manuais é o filme $O$ Fabuloso Destino de Amelie Poulain, de Jean-Pierre Jeunet (2002). Em Hollywood, a maioria dos

SOUZA,Pedro Felipe Pinho. o Look nos filmes Direito de Amar, Azul É A Cor Mais Quente e Moonlight: sob a luz do luar.

PóS:Revista do Programa de Pós-graduação em Artes da EBA/UFMG. v.9, n.17: mai. 2019. Disponivel em <https://eba.ufmg.br/revistapos $>$

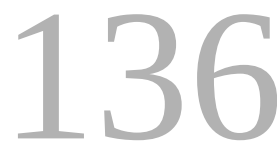


filmes tende para uma paleta específica, como constata o estudo produzido por Edmund Helmer e Qinghui Ji (2012) em seu artigo: "10 "Qualquer um que assista suficientes filmes rapidamente perceberá um gosto de Hollywood por laranjas e azuis, e não há dúvidas de que elas representam a paleta padrão da indústria ${ }^{11}$ (HELMER; JI, 2012, p. 1, tradução nossa). Esse visual, tornou-se famoso ganhando o nome de "Teal and Orange", um look que contrasta tons de laranjas com cianos e azuis. Tornou-se uma "moda" visual entre os principais blockbusters ${ }^{12}$ hollywoodianos como Homem de Ferro 2, de Jon Favreau (2010), toda a série Transformers, de Michael Bay (2007-2017), Mad Max: Estrada da Fúria, de George Miller (2015) entre outros.

Essas são apenas algumas referências, diversas paletas podem ser criadas e utilizadas das mais diferentes maneiras. Cada personagem pode possuir uma paleta diferente para suas roupas, para a iluminação, maquiagem, ou uma aplicação digital específica, um look próprio que irá acompanhar determinado personagem. Atrelar determinada paleta à narrativa e construir uma simbologia interessante e compreensível é o desafio dos cineastas. A criatividade do autor é demonstrada na obra ao analisar o modo como estão atreladas cor, simbologia e narrativa em seu filme. O desenvolvimento do look é parte do processo de desenvolvimento dessa simbologia. Mesmo que a referência seja extrafílmica, sua compreensão só será completa caso o look esteja de acordo com a proposta.

\section{CAMINHOS DA COR: Direito de amar, Azul é a cor mais quente e Moonlight}

O desenvolvimento do look se dá na união de diferentes profissionais e decorrentes debates sobre como a experiência imagética final do filme deve ser. $A$ análise da imagem cinematográfica, portanto, pode ser feita sem a necessidade de conhecer os processos criativos pelo qual a obra e esses profissionais passaram. Pela inspeção da narrativa cinematográfica e sua relação com os aspectos cromáticos da imagem, é possível analisar o caminho escolhido para a

SOUZA,Pedro Felipe Pinho. 0 Look nos filmes Direito de Amar, Azul É A Cor Mais Quente e Moonlight: sob a luz do luar.

PóS:Revista do Programa de Pós-graduação em Artes da EBA/UFMG. v.9, n.17: mai. 2019. Disponivel em <https://eba.ufmg.br/revistapos $>$ 
utilização de determinada cor no decorrer do filme, consequentemente, é possível analisar como o look foi desenvolvido. O entendimento do look proposto, quando em consonância com a narrativa, dessa forma, tem, no que concerne à utilização da cor, alguma associação definida, seja ela usual, cultural e historicamente construída, ou diferente, em busca de uma nova construção simbólica. O objetivo ao analisar os filmes, neste artigo, é encontrar essas associações e, assim, poder analisar a obra cinematográfica pelo viés da cor.

O filme Direito de Amar (A single man), dirigido em 2009 por Tom Ford, é um exemplo das experimentações com software de colorização digital, e com as possibilidades trazidas no decorrer do processo denominado color grading, que produziram o look da obra. O colorista da obra foi Stephen Nakamura e, o diretor de fotografia, Eduard Grau. (THOMPSON, 2015, p. 68). O filme narra a história de George (Colin Firth), um professor universitário homossexual que perdeu o parceiro de longos anos, Jim (Matthew Goode), em um acidente de carro. Abalado emocionalmente e deprimido, o professor planeja o suicídio. Ele tenta organizar tudo para que ninguém perceba sua decisão, em especial seus alunos e sua velha amiga Charlotte (Julianne Moore). O filme se passa ao longo do dia do professor universitário e de seus preparativos para o suicídio. Ao longo desse dia o espectador tem acesso às memórias do professor, ao lado de Jim, antes da morte deste.

O filme utiliza os níveis de saturação para determinar o humor e o estado de espírito do personagem principal. A depressão que toma conta do professor e sua caminhada ao suicídio é marcada por uma paleta acinzentada, há poucas cores vivas e saturadas, as cenas são constituídas basicamente por variações de cinzas (FIGURA 2). Boa parte do filme se passa com essa paleta cromática. É o cotidiano do professor sem seu parceiro. Temos, portanto, um exemplo da imagem sem saturação associada à ideia de perda, depressão e vontade de suicídio do protagonista. Essa paleta também marca o tempo presente do filme, para que este

SOUZA,Pedro Felipe Pinho. o Look nos filmes Direito de Amar, Azul É A Cor Mais Quente e Moonlight: sob a luz do luar.

PóS:Revista do Programa de Pós-graduação em Artes da EBA/UFMG. v.9, n.17: mai. 2019. Disponivel em <https://eba.ufmg.br/revistapos $>$ 
não seja confundido com as memórias do professor, que aparecem no decorrer do filme. Essas memórias são saturadas, nelas Jim está vivo e sua presença traz "cor" (saturação) para vida de George.

É importante ressaltar que o ponto de vista da obra se dá pela visão e percepção da personagem principal. O espectador percebe aquilo que George percebe. Se para George a memória com seu amado é viva e colorida, é dessa maneira que se percebe também a memória por meio da imagem. É nesse sentido que as cores são utilizadas no filme, em consonância com a percepção da personagem, buscando simbologias usuais para retratar suas emoções. George, ao longo do seu dia, no entanto, experimenta outras sensações; o flerte e a possibilidade amorosa com outros personagens, por exemplo. Um aluno que demonstra interesse pelo professor e um desconhecido em uma loja de conveniência se aproximam do protagonista com a intenção de relacionarem-se amorosamente com ele. Esses dois momentos são interessantes, pois, ao experimentar essas sensações amorosas, a paleta de cor do filme se transforma instantaneamente.

Mas a compreensão de uma estilização cromática de Direito de Amar situa-se mais fortemente na era digital como uma recusa do natural ou, em vez disso, re-imagina a visão natural como expandida, encarnada nas transformações perceptivas que George sofreu e que a cor digital nos mostrou ${ }^{13}$ (THOMPSON, 2015, p. 79, tradução nossa).

A possibilidade de superar o amor perdido (Jim) com outra pessoa transforma a vida de George e, consequentemente, a paleta de cores do filme muda, tornando-se saturada. É possível observar essa mudança instantânea na sequência de frames do momento em que o professor inicia o flerte com o desconhecido na saída de uma loja de conveniência (FIGURA 2).

Direito de Amar optou por trazer o controle de saturação como passível de ser associado simbolicamente a elementos do roteiro, proporcionando um embate entre saturado e sem saturação, possibilitando diferentes abordagens para a obra. No caso do drama protagonizado por Colin Firth, a imagem também situa o espectador, ajudando, dessa forma, na compreensão temporal e espacial do filme. $\mathrm{O}$

SOUZA,Pedro Felipe Pinho. 0 Look nos filmes Direito de Amar, Azul É A Cor Mais Quente e Moonlight: sob a luz do luar.

PóS:Revista do Programa de Pós-graduação em Artes da EBA/UFMG.v.9, n.17: mai. 2019. Disponivel em <https://eba.ufmg.br/revistapos $>$ 
tempo presente é marcado pela paleta sem saturação, enquanto o passado pela paleta saturada. Por outro lado, os momentos em que a imagem está saturada e se passam no tempo presente da realidade diegética tiveram um aumento repentino que pôde ser verificado pelo espectador no decorrer do tempo da cena, e não entre os cortes, garantindo que aqueles acontecimentos estejam no presente exatamente porque é possível observar a mudança na imagem. Isso faz com que essas imagens carreguem a simbologia associada ao passado do restante do filme.
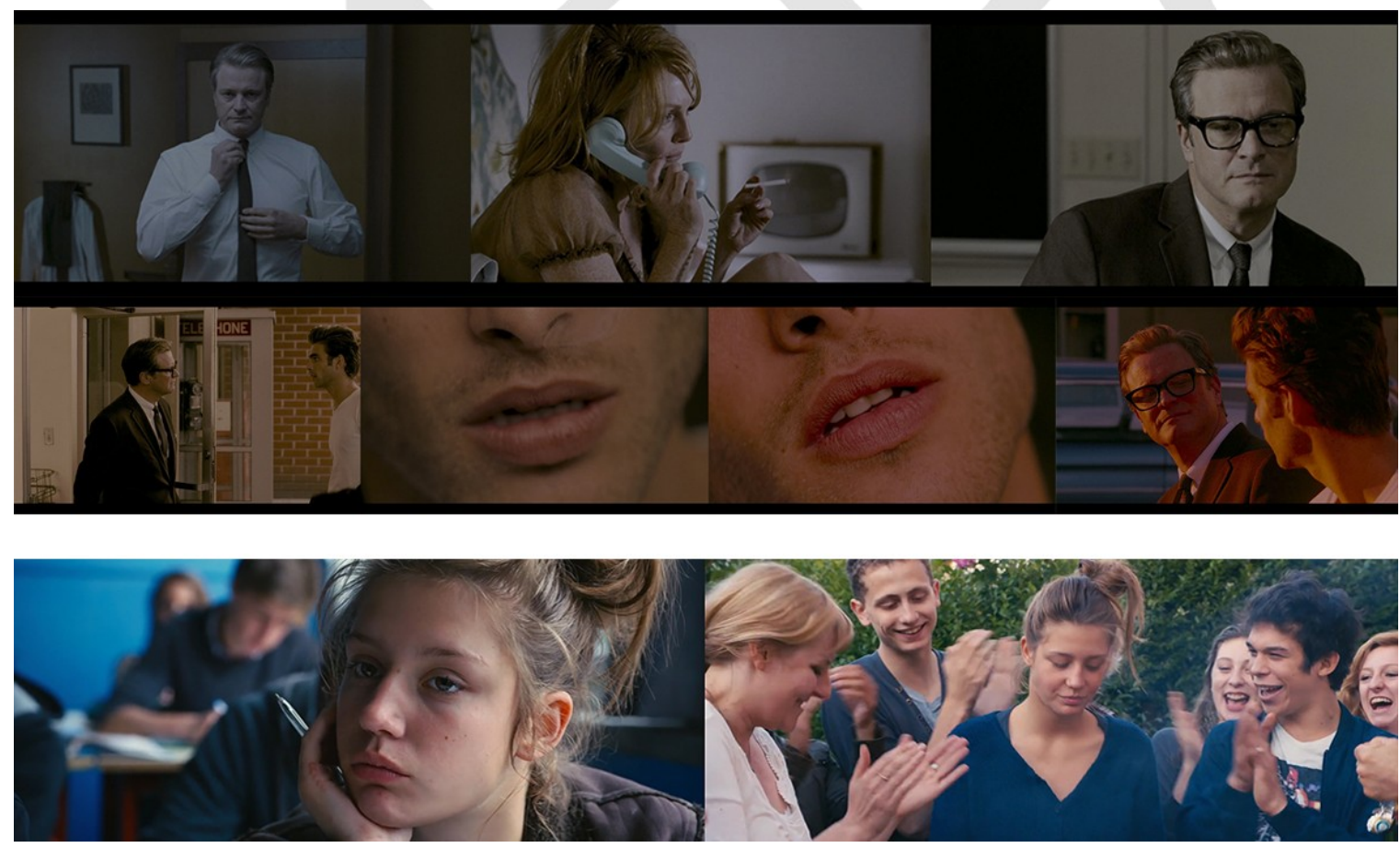

Figura 2 - Imagens iniciais e sequência com a saturação aumentando Legenda: ๑ Frames do filme Direito de Amar, Tom Ford, 2009 (acima). Cenas iniciais do filme, com Adèle rodeada de azul. | ( F Frames do filme Azul é a cor mais quente, Abdellatif Kechiche, 2013 (abaixo).

Fonte: Imagem produzida pelo autor

Em 2013, o franco-tunisiano Abdellatif Kechiche dirigiu e roteirizou o filme Azul é a cor mais quente (La vie d'Adèle), vencedor da Palma de Ouro do mesmo ano. O nome sugestivo que o filme recebeu em outros países já indica as possibilidades

SOUZA,Pedro Felipe Pinho. 0 Look nos filmes Direito de Amar, Azul É A Cor Mais Quente e Moonlight: sob a luz do luar.

PóS:Revista do Programa de Pós-graduação em Artes da EBA/UFMG. v.9, n.17: mai. 2019. Disponivel em <https://eba.ufmg.br/revistapos $>$

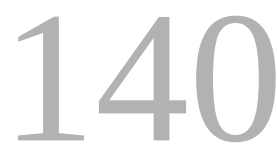


cromáticas que a obra pode suscitar. O intuito de analisar esse filme, no entanto, entra em consonância com a possibilidade de pensar e analisar discursos e caminhos narrativos com a cor que não sejam usualmente utilizados de forma simbólica, mas que possibilitem utilizações criativas.

Em se tratando do look, Direito de amar demonstrou como o colorista pode modificar a imagem e produzir simbologias que caminhem com a narrativa contada. Azul é $a$ cor mais quente, por sua vez, utiliza os elementos do cenário e figurinos, prioritariamente, para construir esse caminho com a cor.

O filme conta a história de Adèle (Adèle Exarchopoulos), uma jovem adolescente que mora em Paris e se apaixona por Emma (Léa Seydoux), estudante de artes plásticas em uma faculdade da mesma cidade. O look do filme pode ser analisado para tentar compreender a relação estabelecida entre essas duas personagens. É interessante, porém, analisar as imagens do filme, para perceber as sutilezas do processo de criação do look. Adèle é a personagem principal, é ela que guiará as percepções do espectador. A principal cor a aparecer em praticamente todas as imagens da produção é a azul. Nas vestes, cenários, paredes, objetos, maquiagem, o azul toma conta de boa parte das cenas da produção (FIGURA 2). No entanto, apesar da cor azul envolver a personagem, nem sempre ela utiliza essa cor em suas vestimentas; e outras cores aparecem durante o primeiro ato da projeção.

Adèle pertence a uma classe menos favorecida de parisienses; ela precisa lutar, assim como seus colegas de sala, por melhores condições para educação; tem medo do desemprego e, ao mesmo tempo, tenta conter os impulsos e inseguranças trazidos pela adolescência. "O filme retrata um 'ser a procura de si mesmo'" (FILHO; FERREIRA JÚNIOR; MACEDO, 2017, p. 25), em especial, no que diz respeito à atração sexual e à relação com meninos e meninas. Suas inseguranças são demonstradas por meio de suas vestimentas e dos elementos ao seu

SOUZA,Pedro Felipe Pinho. 0 Look nos filmes Direito de Amar, Azul É A Cor Mais Quente e Moonlight: sob a luz do luar.

PóS:Revista do Programa de Pós-graduação em Artes da EBA/UFMG.v.9, n.17: mai. 2019. Disponivel em <https://eba.ufmg.br/revistapos $>$

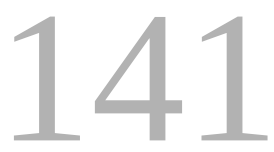


redor. Em sua festa de aniversário, por exemplo, por se sentir feliz e bem, ela veste essa cor e, praticamente, todos ao redor dela também. O azul também está presente quando ela se envolve com Emma, por quem se apaixona.

Ao se envolver com um menino, no entanto, a personagem veste marrons e amarelos. O encontro de Adèle e a relação sexual com Thomas (Jeremie Laheurte) são marcados pela pouca presença do azul nas cenas ou, quando há o azul, está pouco saturado e presente com outras cores, também em destaque. $\mathrm{Na}$ cena de sexo, os planos fechados conferem o comum tom avermelhado, próprio desse tipo de cena, conforme uma construção simbólica usual utilizaria. A cor acinzentada das paredes e o lençol com um azul pouco saturado mostram Adèle desconfortável, sem a forte presença da cor azul nos cenários, como nos momentos anteriores.

Todavia, um momento crucial modifica a percepção da associação inicial do azul apenas com a personagem de Adèle. O primeiro encontro entre ela e Emma pelas ruas de Paris. Esse momento mostra pela primeira vez Emma e seu cabelo azul. E, a partir daí, quanto mais Adèle se aproxima e se apaixona por Emma, mais a cor azul a envolverá. O azul passa, portanto, a representar não somente a presença de Adèle, mas sua plenitude, sua felicidade e sua autoaceitação. Tendo em vista as dificuldades da adolescência e o quanto o processo de aceitação perante a sociedade é complicado nesse período da vida, ainda mais se descobrindo (bi)homossexual, pode-se ver em diversas imagens a luta de Adèle para ser aceita e como o azul é utilizado para retratar situações com as quais a personagem irá se deparar. A cor azul domina a projeção e, quanto mais presente em cena, mais determinada a personagem está em encontrar e determinar sua personalidade e amor próprio.

Diversas cenas do filme mostram a personagem envolta na cor azul e comprovam essa percepção aqui proposta. Uma cena interessante para compreender isso é a de sexo entre as duas personagens principais. Contra-

SOUZA,Pedro Felipe Pinho. 0 Look nos filmes Direito de Amar, Azul É A Cor Mais Quente e Moonlight: sob a luz do luar.

PóS:Revista do Programa de Pós-graduação em Artes da EBA/UFMG. v.9, n.17: mai. 2019. Disponível em <https://eba.ufmg.br/revistapos $>$

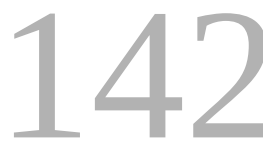


pondo-se à primeira cena de sexo do filme, o lençol azul e a iluminação da cena contribuem para a construção de imagens que, em outras obras são utilizados tradicionalmente os tons de vermelhos, em uma associação usual dessa cor com paixão, amor e sensualidade como na cena de sexo anterior. No caso desse filme, o azul do lençol e o cenário ganham destaque na imagem, amenizando o tom avermelhado comum à pele das atrizes.

Uma primeira análise que poderia ser feita diferenciaria relações heterossexuais das homossexuais trazidas pela cor azul. No entanto, seria simplista acreditar que essa é a única associação proposta pelo filme para essa cor. As cenas em que há forte presença de azul não são somente as de cunho homossexual, mas as de felicidade da personagem, do seu encontro com a liberdade de poder ser quem ela quer ser, e de ser, finalmente, aceita, seja por Emma, pelos amigos, seja pela família.

No decorrer do filme, Adèle se desentende com Emma. A principal marca desse desentendimento é causada pela mudança de cor no cabelo de Emma, não mais azul. No entanto, não somente no cabelo de Emma, o azul começa a perder destaque. Em outras situações, vemos vermelhos compondo as imagens, nos figurinos e cenários, e os azuis aparecendo mais claros ao redor de Adèle. É nas imagens onde o vermelho e o azul aparecem que se percebe a associação entre a homossexualidade, felicidade e autoaceitação de Adèle, em oposição à heterossexualidade, confusão e infelicidade da personagem.

Nas últimas cenas do filme, não vemos mais azuis em torno de Adéle, apenas cinzas, pretos e branco, em uma possível constatação de que o amor por Emma realmente acabou. A percepção de Adèle de não pertencimento é simbolizada pelo vestido azul que a personagem utiliza. Apesar da tristeza, Adèle segue vestindo azul, uma constatação de que a personagem continua seu processo de entender quem ela é e ser aceita (FIGURA 3).

SOUZA,Pedro Felipe Pinho. 0 Look nos filmes Direito de Amar, Azul É A Cor Mais Quente e Moonlight: sob a luz do luar.

PóS:Revista do Programa de Pós-graduação em Artes da EBA/UFMG. v.9, n.17: mai. 2019. Disponivel em <https://eba.ufmg.br/revistapos $>$

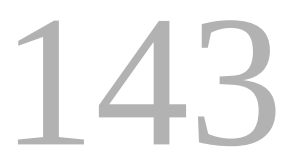


Uma das propriedades da colorização digital, como referenciado no início deste artigo, é a de simular os processos fotoquímicos possíveis através dos negativos dos filmes rodados em película. Nesse sentido, um ótimo filme para analisar essa propriedade é Moonlight: sob a luz do luar, de Barry Jenkins (2016), vencedor do Oscar de melhor filme no ano de 2017. A proposta do diretor para contar a narrativa foi dividir o filme em três partes: uma contando a história da infância do personagem principal, outra sua adolescência e, a terceira, o início de sua vida adulta. O motivo do filme ser interessante para perceber as propriedades da colorização digital deve-se ao fato de ele emular três diferentes tipos de negativo para cada parte da divisão proposta para o filme. O diretor de fotografia do filme James Laxton e o colorista Alex Bickel são os responsáveis pelas belas imagens da obra e por tornar viável a realização da proposta de emular os três tipos diferentes de negativos de maneira digital.
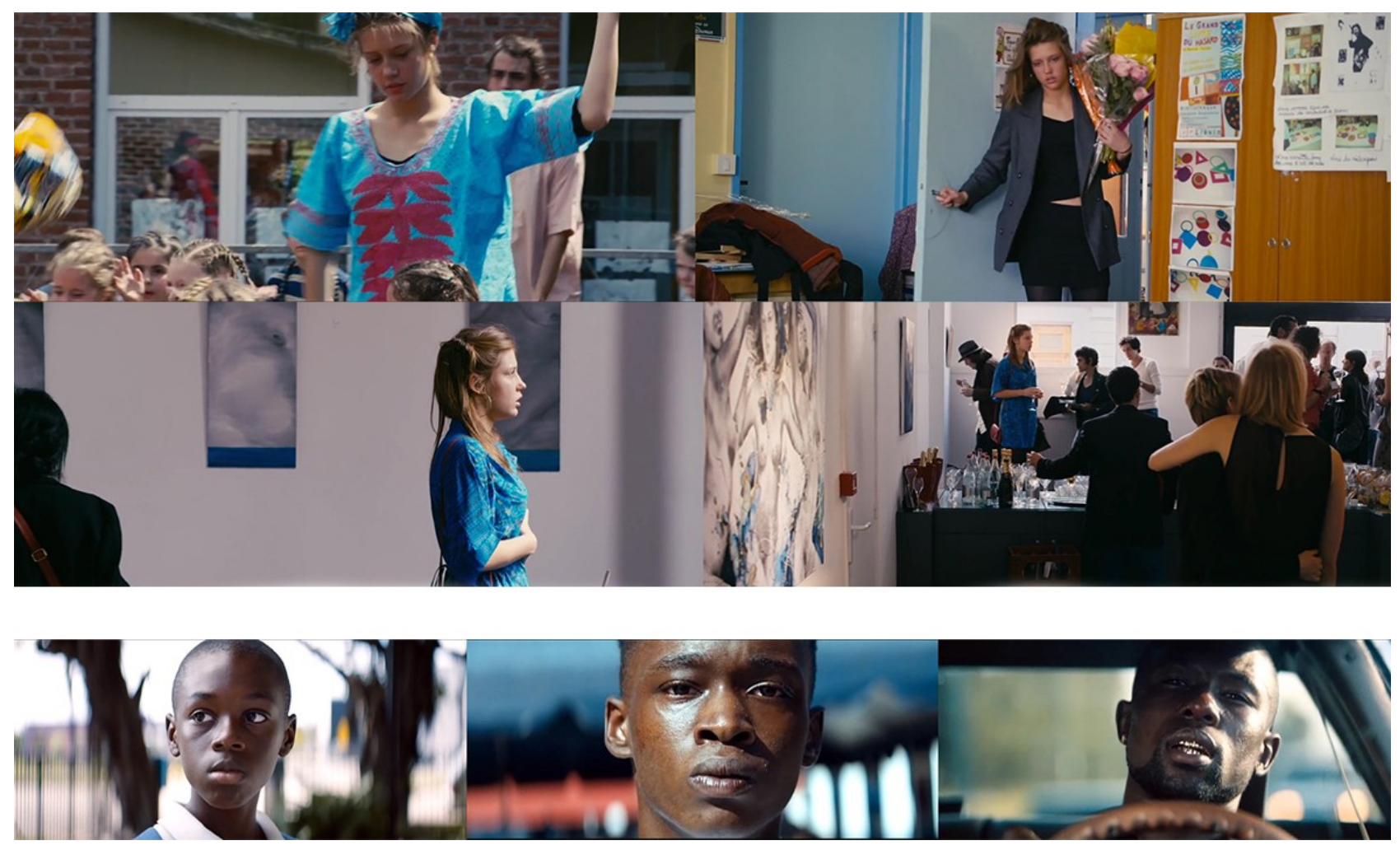

Figura 3 - Cenas finais do filme com azuis menos saturados e cinzas envolvendo Adèle

SOUZA,Pedro Felipe Pinho. 0 Look nos filmes Direito de Amar, Azul É A Cor Mais Quente e Moonlight: sob a luz do luar.

PóS:Revista do Programa de Pós-graduação em Artes da EBA/UFMG.v.9, n.17: mai. 2019. Disponivel em $<\underline{\text { https://eba.ufmg.br/revistapos }>}$

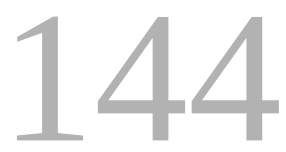


Legenda: | ( Frames do filme Azul é a cor mais quente, Abdellatif Kechiche, 2013. (acima). Os três atos do filme. Infância, adolescência e vida adulta de Chiron. Para cada momento foi emulado um tipo de negativo diferente. | (c) Frames do filme Moonlight: sob a luz do luar, Barry Jenkins, 2016. (abaixo)

Fonte: Imagem produzida pelo autor

O primeiro capítulo foi definido para imitar o negativo de filme da Fuji, que de acordo com Bickel, é um pouco mais quente e traz muita textura no tom de pele. O terceiro capítulo usou um Kodak modificado, que segundo Bickel é menos "restrito" e fornece mais estouro e brilho para a imagem. O capítulo mais distinto de "Moonlight" é o segundo, que Bickel atribui ao antigo filme da Agfa, que estava configurado para simular. O negativo alemão simulado era conhecido por adicionar um tom ciano aos highlights das imagens, o que dá a cor azul esverdeada ${ }^{14}$ (O'FALT, 2016, tradução nossa).

Ao emular diferentes negativos os realizadores foram capazes de ampliar as suas possibilidades, algo que, utilizando a via fotoquímica tradicional, poderia se tornar inviável, ou, ao menos, difícil de conseguir. Pelo fato de trabalhar com atores negros, as dificuldades foram ainda maiores, tendo em vista o controle preciso de contraste necessário para que a pele dos atores não ficasse escura demais ou o restante da imagem clara demais. ${ }^{15}$ Essa possibilidade só foi possível com as ferramentas digitais. A colorização digital permitiu a Laxton e Bickel a criação de três looks diferentes, que remetem aos padrões de imagem antigos. Além disso, ele e o diretor de fotografia conseguiram chegar a limites muito difíceis.

Moonlight é também um exemplo interessante para uma análise das cores escoIhidas para os momentos da obra e da sua utilização criativa. O personagem principal do filme chama-se Chiron. No primeiro ato do filme, ele é chamado de Little (pequeno, em inglês), representado por Alex R. Hibbert. O início do filme mostra Little fugindo de outros garotos que o perseguem e zombam pelo fato de ele ser "diferente"; ele é, então, salvo por Juan, conhecido por Blue (azul, em inglês), representado por Mahershala Ali, um traficante de Miami, onde ambos vivem.

SOUZA,Pedro Felipe Pinho. o Look nos filmes Direito de Amar, Azul É A Cor Mais Quente e Moonlight: sob a luz do luar.

PóS:Revista do Programa de Pós-graduação em Artes da EBA/UFMG.v.9, n.17: mai. 2019. Disponivel em $<\underline{\text { https://eba.ufmg.br/revistapos }>}$

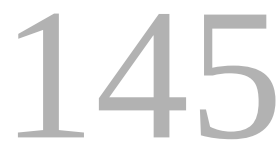


Blue leva Little para casa e, com a namorada Teresa (Janelle Monáe), cuida do garoto. Blue encontra a mãe de Little, Paula (Naomie Harris), que não fica nada feliz ao ver o garoto com o traficante. No entanto, Paula compra drogas com Juan e muitas vezes maltrata o filho. Moonlight tem um primeiro ato cheio de simbologias e utilizações interessantes da cor. Assim como em Azul é a cor mais quente, a obra também utiliza o azul como a cor do 'descobrir-se a si próprio' e da busca de 'ser quem se quer ser'. Ao analisar o filme, Storey (2016) afirma que

O filme é permeado por um esquema de cores azul e vermelho que, gradualmente, é ofuscado conforme a concepção de Chiron de si mesmo amadurece. O vermelho, ao que parece, prevalece quando Chiron ou aqueles que o rodeiam entendem como os outros o define e atualizam seus estereótipos. Seu atormentador da escola secundária ostenta uma camisa vermelho sangue e sua mãe está banhada em luz vermelha quando grita com Chiron, antes de fechar a porta na cara dele. Mas quando Juan Ihe diz que ele deve decidir quem ele quer ser e diz a Chiron que ele não pode deixar ninguém tomar essa decisão por ele, aparece um Chiron centrado entre uma massa de azul: móveis, cortinas e o céu ${ }^{16}$ (STOREY, 2016, tradução nossa).

Nas cenas citadas é interessante ressaltar como essa dualidade azul - autoconhecimento, aceitação de si-, e vermelho - visão dos outros sobre você, não aceitação-, é caracterizada no filme e tem seu principal embate na luz que banha a mãe de Chiron. Diferentemente do que afirma Storey, a luz que banha Paula é magenta (a mistura de azul e vermelho), mostrando, assim, a luta da mãe em aceitar o filho homossexual que irá culminar em um diálogo entre os dois no terceiro ato e na redenção da mãe. Pode-se dizer que, no filme, os personagens que utilizam o vermelho ou irão julgar outros, ou dependerão da opinião de outros para tomar decisões.

Nesse filme, assim como em Azul é a cor mais quente, a cor azul envolve o personagem em diversos momentos. Seja em casa, seja na escola, Chiron está sempre rodeado de elementos azuis ou iluminado por luzes dessa cor. Suas vestes seguem esse padrão, e a oposição azul / vermelho é importante, assim como no

SOUZA,Pedro Felipe Pinho. o Look nos filmes Direito de Amar, Azul É A Cor Mais Quente e Moonlight: sob a luz do luar.

PóS:Revista do Programa de Pós-graduação em Artes da EBA/UFMG. v.9, n.17: mai. 2019. Disponivel em <https://eba.ufmg.br/revistapos $>$

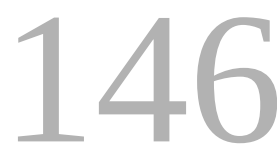


outro filme previamente analisado. Em uma das cenas mais importantes do filme, Juan diz a Little que ele não pode deixar ninguém decidir por ele quem ele vai ser. Essa é a última cena em que vemos Chiron vestindo vermelho.

“Não podemos esquecer em momento nenhum que o homem que vemos no meio e final é a criança que vimos no começo ${ }^{17 "}$ (BEACHLER, 2017, p. 19, tradução nossa). Essa afirmação é muito precisa para auxiliar na análise do filme. A identificação com o personagem principal é dada em função do fato de o espectador acompanhar todas as fases de sua vida. A história de Chiron é a de um personagem em busca de sua personalidade, na luta para encontrar seu espaço no mundo. Para complementar esse sentido, durante a cena em que Chiron, ainda criança, aprende a nadar com Juan, na praia, o traficante diz ao pequeno que, sob a luz do luar, garotos negros ficam azuis. Ou seja, a luz do luar mostraria a verdadeira face dos garotos negros, uma simbologia que envolve a luz da lua cheia e sua capacidade de iluminar, mesmo durante a noite, mesmo durante a escuridão.

Ambos os filmes, Moonlight e Azul é a cor mais quente, tratam de indivíduos em busca de descobrirem-se perante a sociedade da condição (bi)homossexual em que vivem, em meio às turbulências e preconceitos enfrentados na adolescência e desafios da vida adulta. Essa descoberta é representada tanto no primeiro quanto no segundo filme por meio da cor azul, novamente associada a isso no filme de Jenkins.

O tema da homossexualidade é recorrente nas três obras observadas neste artigo. É possível perceber como novas construções simbólicas sobre essa temática podem ser desenvolvidas, e como o look é fundamental para percepção das imagens cinematográficas. Diferentemente dos dois últimos filmes observados, Direito de Amar apresenta uma paleta com poucos azuis e imagens opondo cinzas a vermelhos e laranjas; a felicidade do personagem não estava em sua 
descoberta da condição homossexual, nem em se aceitar dessa maneira, mas, sim, em mostrar seu amor ao outro. Não era o amor próprio que iria "salvar" George, mas, sim, o amor de outrem.

O embate, portanto, não gira em torno da condição de uma oposição entre homossexualidade e heterossexualidade. Em um contexto cada vez mais intolerante e individualista, o azul nos últimos dois filmes mostra sua força ao buscar uma relação de pertencimento dos personagens em uma sociedade que os quer cada vez mais distantes. A aceitação que o azul traz, portanto, não é somente de um amor próprio individual, não basta somente aceitar a condição homossexual individualmente. É a aceitação coletiva que esse azul busca, diferentemente, portanto, da saturação no primeiro filme, que traz os personagens sempre às escondidas e bem na sua condição.

A compreensão de todo o desenvolvimento da cor em obras cinematográficas pode culminar em construções de simbologias e, consequentemente, proporcionar comparações entre diferentes filmes que estejam sob uma mesma lógica visual. A cor é o elo principal que possibilita novas construções simbólicas com os elementos culturais, como os filmes. 


\section{REFERÊNCIAS}

BARROS, L. R. A cor inesperada: uma reflexão sobre os usos criativos da cor. Tese (Doutorado em Design e Arquitetura) - FAUUSP. Orientador: Silvio Melcer Dworecki, São Paulo, 2012.

BEACHLER, Hannah. Color Patterns: the production designer of Moonlight builds worlds that breathe with emotion. Film Comment (Film Society of Lincoln Center), v. 53, n. 1, p. 18-19, 2017.

COLOUR IN STORYTELLING. Youtube, 2015. Disponível em: <www.youtube.com/watch? $\mathrm{v}=a X g F c N U W q X 0 \& f e a t u r e=y o u t u . b e>$. Acesso em: 20 jul. 2016.

COSTA, M. H. Cores \& filmes: um estudo da cor no cinema. Curitiba, PR: CRV, 2011.

COUCHOT, E. A tecnologia na arte: da fotografia à realidade virtual. (S. Rey, Trans.) Porto Alegre: Editora da UFRGS, 2003.

DUBOIS, P. Cinema, vídeo, Godard. São Paulo: Cosac Naify, 2004.

FILHO, Otacílio Amaral; FERREIRA JÚNIOR, Sérgio do Espírito Santo; MACEDO, Tarcízio. O choque do real na narrativa cinematográfica Azul é a Cor Mais Quente: reflexões sobre a cultura estética. Sessões do Imaginário. v. 22, n.37, p. 20-29, 2017.

GUIMARÃES, L. A cor como informação: a construção biofísica, lingüistica e cultural da simbologia das cores. São Paulo: Annablume, 2001.

HELMER, E.; JI, Q. Film Classification by Trailer Features. Stanford University, 2012.

Disponível em: <http://cs229.stanford.edu/proj2012/HelmerJi-

FilmClassificationByTrailerFeatures.pdf>. Acesso em: 14 dez. 2018.

HURKMAN, A. V. Color Correction Look Book: creative grading techniques for film and video. Berkeley, Califórnia: Peachpit Press, 2014.

Color Correction Handbook: Professional Techniques for Videos and Cinema.

Berkeley, California, EUA: Peachpit Press, 2011.

KALMUS, N. Color Consciousness. Journal of the Society of Motion Picture Engineers, $p$. 139-147, 1935.

MOURA, E. Da Cor. Santa Catarina: iPhoto Editora, 2016.

O'FALT, Chris. Moonlight' Glow: Creating the Bold Color and Contrast of Barry Jenkins' Emotional Landscape. 2016. Disponível em: <https://www.indiewire.com/2016/10/moonlightcinematography-color-barry-jenkins-james-laxton-alex-bickel-1201740402/>. Acesso em: 11 mar. 2017.

SOUZA,Pedro Felipe Pinho. O Look nos filmes Direito de Amar, Azul É A Cor Mais Quente e Moonlight: sob a luz do luar.

PóS:Revista do Programa de Pós-graduação em Artes da EBA/UFMG. v.9, n.17: mai. 2019. Disponivel em $<\underline{\text { https://eba.ufmg.br/revistapos }>}$

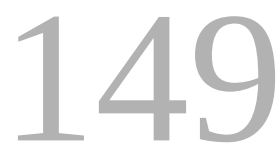


PRINCE, S. The Emergence of Filmic Artifacts Cinema and Cinematography in the Digital Era. Film Quarterly, University of California, v. 57, n. 3, p. 24-33, Spring, 2004.

Digital Visual Effects in Cinema: The Seduction of Reality. New Jersey: Rutgers University Press, 2011.

SOUZA, Pedro F. P. O look no cinema digital. Dissertação (Mestrado em Artes Visuais) - IA - Unicamp. Campinas, 2018.

STOREY, Elliot. 'Moonlight' uses color, characters to create excellent, carefully crafted portrait. Nov. 2016. Disponível em: <https://tuftsdaily.com/arts/2016/11/14/moonlight-usescolor-characters-create-excellent-carefully-crafted-portrait/>. Acesso em: 3 nov. 2017.

YUMIBE, J. Moving Color: Early Film, Mass Culture, Modernism. New Jersey: Rutgers University Press, 2012.

THOMPSON, Kirsten Moana. Falling in (to) Color: Chromophilia and Tom Ford's A Single Man (2009). The Moving Image, University of Minnesota Press, v. 15, n.1, p. 62-84, 2015.

SOUZA,Pedro Felipe Pinho. 0 Look nos filmes Direito de Amar, Azul É A Cor Mais Quente e Moonlight: sob a luz do luar.

PóS:Revista do Programa de Pós-graduação em Artes da EBA/UFMG.v.9, n.17: mai. 2019. Disponivel em <https://eba.ufmg.br/revistapos $>$ 


\section{NOTAS}

1 Texto baseado na dissertação defendida em janeiro de 2018 no Instituto de Artes - Unicamp: "O look no cinema digital" (SOUZA, 2018).

2 Profissional responsável pelo processo de colorização digital.

3 É possível entender melhor essa técnica por meio do vídeo: <https://www.youtube.com/watch? v=vubuBrcAwtY>. Acesso em: 27 set. 2017.

$4 \quad$ I would argue that color correction refers to a process that is more technical in nature, of making adjustments to correct clear qualitative problems in an image, bringing it to a fairly neutral state, whereas grading refers to a more intensive process of developing an appropriate overall style for the image, relative to the narrative and artistic needs of a program.

5 Materia do jornal Folha de São Paulo sobre a crise no setor de efeitos especiais hollywoodiano. Disponível em: <http://www1.folha.uol.com.br/ilustrada/2013/03/1253944-hollywood-vive-crise-nosetor-de-efeitos-especiais-produtora-que-levou-o-oscar-faliu.shtml>. Acesso em: 6 set. 2017

6 Only through constructing a broad, aesthetic history of the cinema - one that takes into account past and present analogies - can we come to a richer, more critical understanding of what cinema is and does and can do, particularly now that digital imaging has reminded us once again that cinema's sensuous ontology is, and hopefully will remain, an open and pressing question.

7 Digital Video - Video digital.

8 Entre os anos de 1934 até 1949, Natalie Kalmus assinou praticamente todas as obras produzidas pela empresa como supervisora da cor das obras.

9 Alguns exemplos são: <http://moviesincolor.com>,<http://thecolorsofmotion.com/films>, <http://www.shutterstock.com/blog/movies-in-color-film-color-palettes>. Acessos em: 28 set. 2017.

10 Mais informações podem ser encontradas em: <http://boxofficequant.com/oranges-and-blues/> . (Helmer, Statistic and films, 2013).

11 Anyone who watches enough film becomes quickly used to Hollywood's taste for oranges and blues, and it's no question that these represent the default palette of the industry.

12 Blockbusters são filmes que possuem um grande orçamento e apelo popular dado por um investimento massivo na publicidade e divulgação da obra.

13 But $A$ Single Man's embrace of chromatic stylization situates it most strongly in the digital age as a refusal of the natural, or rather reimagines the natural as expanded vision, incarnated in the perceptual transformations that George has undergone and that digital color has shown us.

14 The first chapter was set to emulate Fuji film stock, which according to Bickel, is a little warmer and brings out a lot of texture in the skin tone. The third chapter used a modified Kodak stock, which according to Bickel is less "restrained" and provides more pop and shine to the image. The most distinct looking chapter of "Moonlight" is the second, which Bickel credits to the old Agfa film stock it was set to mirror. The long retires German film stock was known for adding a cyan to the images highlights, wich is what gives the greenish-blue hue.

15 O principal problema ocorre em função do desenvolvimento dos negativos, que privilegiavam a pele branca. <https://www.geledes.org.br/questao-de-pele-os-cartoes-shirley-e-os-padroes-raciaisque-regem-industria-visual/> e <https://revistazum.com.br/revista-zum-10/racismo-padroes-industriabrasil/>. Acessos em: 14 nov. 2017. 


\section{NOTAS}

16 The film is pervaded by a blue-and-red color scheme that gradually blurs as Chiron as conception of himself matures. The red, it seems, pervades when Chiron or those around him hew to how others define them and actualize stereotypes. His high school tormentor sports a blood-red shirt, and his mother is bathed in red light when she shouts Chiron down before shutting her door on him to turn a trick. But when Juan tells him he must decide who he wants to be and tells Chiron that he can't let nobody make that decision for you, a Chiron is centered among a mass of blue: furniture, curtains and the sky.

17 We could never at any moment forget that the man we see in the middle and end was the child we saw in the beginning. 